This item was submitted to Loughborough's Research Repository by the author.

Items in Figshare are protected by copyright, with all rights reserved, unless otherwise indicated.

\title{
A British university case study of the transitional experiences of student- athletes
}

PLEASE CITE THE PUBLISHED VERSION

http://dx.doi.org/10.1016/j.psychsport.2015.04.002

PUBLISHER

(C) Elsevier

VERSION

AM (Accepted Manuscript)

\section{PUBLISHER STATEMENT}

This work is made available according to the conditions of the Creative Commons Attribution-NonCommercialNoDerivatives 4.0 International (CC BY-NC-ND 4.0) licence. Full details of this licence are available at: https://creativecommons.org/licenses/by-nc-nd/4.0/

\section{LICENCE}

CC BY-NC-ND 4.0

\section{REPOSITORY RECORD}

Brown, Daniel J., David Fletcher, lan P.D. Henry, Andy Borrie, Jo Emmett, Alan Buzza, and Simon Wombwell. 2019. "A British University Case Study of the Transitional Experiences of Student-athletes". figshare. https://hdl.handle.net/2134/20951. 
A British University Case Study of the Transitional Experiences of Student-Athletes

Date of submission: October 30, 2014

22 Date of resubmission: March 04, 2015

23 Date of resubmission: April 1, 2015

24 Date of resubmission: April 6, 2015

Date of acceptance: April 7, 2015 (2015) A British university case study of the transitional experiences of student-athletes, Psychology of Sport and Exercise Volume 21, November 2015, Pages 78-90 
2 Objectives: Within Great Britain, increasing numbers of elite sport performers are attending

3 higher education institutions. The current study presents an exploration of the transitional

4 experiences of these individuals at a specific British university. Wylleman and Lavallee's

5 (2004) developmental model on transitions faced by athletes and Stambulova's $(1997,2003)$

6 athletic career transition model were used to provide the theoretical foundation of inquiry.

7 Design and method: An instrumental case study design was adopted to provide an in-depth

8 analysis of student-athletes' experiences at a university. The case university was selected

9 based on its provision of elite sport support services. To acquire a holistic understanding,

10 interviews were conducted with current and recently graduated student-athletes from the

11 university, and focus groups were run with university staff (viz. administrators, coaches, and support staff). Qualitative data were analyzed using a thematic framework approach.

Results: Elite student-athletes at the British university were found to experience simultaneous athletic, academic, psychological, and psychosocial transitions. To overcome the transitional demands, student-athletes were found to draw on a variety of internal (e.g., self-awareness) and external (e.g., academic flexibility) resources and to implement coping strategies (e.g., seeking social support). Potential barriers to successful transitions were also identified (e.g., parental overprotection).

Conclusions: These findings advance the limited existing literature on British university student-athletes' transitional experiences and suggestions are provided for how other universities can enhance provision for their elite student-athletes. Keywords: career transition, collegiate, development, dual role, performance, sport, talent 
A British University Case Study of the Transitional Experiences of Student-Athletes Within Great Britain, university student-athletes represent a population of growing interest and importance to sport researchers and policy makers. This elevated attention is due, in part, to the significant number of talented and elite sport performers attending further and higher education institutions (Haley \& Saghafi, 2012; Podium, Universities UK, \& British Universities \& Colleges Sport, 2012) and to the increased awareness of the demands faced by athletes during these years (Stambulova, Alfermann, Statler, \& Côté, 2009; Wylleman \& Lavallee, 2004). To elaborate, universities are increasingly becoming 'hubs' for athletes as they can provide the support and flexibility that best enable performers to continue their sporting career (Aquilina, 2013). For example, Aquilina (2013) noted that universities may afford greater access to, and provision of, established support networks, facilities, and flexible academic programs. Furthermore, during the years of 18 and 21 athletes from most sports ${ }^{1}$ experience a normative transition from youth to senior aged competitor (Stambulova, 1994) and attempt to become a mastery level performer (Wylleman \& Lavallee, 2004); a facilitative university environment can aid this development. Indeed, between the 1992 Barcelona and 2012 London Olympic Games, 65\% of British gold medalists had been to university (British Universities \& Colleges Sport [BUCS], 2012). The simultaneous transitions in academic (i.e., high school to university/college) and athletic development are likely to be stressful for student-athletes as they experience strain from numerous and competing demands (Knowles \& Lorimer, 2014; Miller \& Kerr, 2002; Petitpas, Brewer, \& Van Raalte, 2009). The athletic transition from development to mastery performer, for example, may result in an athlete struggling to meet on-field (e.g., training) and off-field (e.g., parent) expectations (Bruner, Munroe-Chandler, \& Spink, 2008; Finn \&

\footnotetext{
${ }^{1}$ It is acknowledged that the transition may occur earlier in athletes participating in sports where peak performance is achieved before biological maturity (e.g., figure skating, women’s gymnastics).
} 
1 McKenna, 2010; Stambulova, Franck, \& Weibull, 2012). Furthermore, the academic

2 transition to higher education may lead to changes in place of residence, increased distance

3 from friends and family, and new personal and academic responsibilities (Lowe \& Cook,

4 2003; MacNamara \& Collins, 2010). Academic and athletic transitions are not the only

5 developmental changes to occur at this time, however, as athletes also experience potentially

6 stressful and impactful changes in their psychosocial and psychological development

7 (Wylleman \& Lavallee, 2004). For example, psychosocial transitions occur in the nature of

8 relationships held with parents. More specifically, parents have been shown to provide vital

9 emotional support for athletes traversing difficult transitions during their career (Mills, Butt,

10 Maynard, \& Harwood, 2012; Pummell, Harwood, \& Lavallee, 2008); however, when moving

11 to university, an athlete's access to this support may be reduced and parental influence may

12 be replaced by support from other sources (Falls \& Wilson, 2013). Late adolescence is also a

13 significant period for psychological development with individuals challenged by various

14 developmental tasks (e.g., accepting one’s physique) that shape their self-identity (Rice,

15 1998). For many student-athletes, sport is likely to play a significant role in this process as

16 their sport involvement intensifies during these years (Coakley, 1993) and their perceptions

17 of the importance of sport has been shown to peak at this time (Greendorfer \& Blinde, 1985).

18 A student-athlete's ability to manage and overcome the demands they experience

19 during these concurrent transitions is likely to determine whether they are successful as a

20 senior performer (Bennie \& O'Connor, 2006; Hollings, Mallett, \& Hume, 2014; Pearson \&

21 Petitpas, 1990). Bennie and O’Connor (2006), for example, found that elite track and field

22 athletes who were able to overcome athletic challenges, such as a lack of initial senior level

23 success, were more likely to remain in sport compared to those who were not. If not coped

24 with effectively, the multifaceted demands faced by student-athletes can also have

25 implications for academic performance, mental health, and psychosocial development 
1 (Ferrante \& Etzel, 2009). In relation to the issue of psychosocial development, the time

2 commitments associated with athletic pursuits can leave little time for student-athletes to

3 foster and nurture relationships outside of their sporting milieu (Kimball \& Freysinger, 2003).

$4 \quad$ Without these broader social networks, student-athletes are more likely to feel and be

5 perceived by others as detached from the rest of the student cohort (Shurts \& Shoffner, 2004).

6 This separation, in addition to the elevated social position (e.g., celebrity status) often held by

7 student-athletes, may lead to unstable and shallow relationships and, ultimately, social

8 isolation (Ahlgren-Bedics \& Monda, 2009; Blinde \& Greendorfer, 1992).

In light of the multifaceted transitions experienced by student-athletes at this age, and

the impact of these changes on their success and psychosocial well-being, it is perhaps unsurprising that there have been growing calls to support these, and other, individuals who opt to continue their sport alongside study or employment (see, e.g., Desprez et al., 2008; Preece et al., 2004). In response to these calls, researchers have increasingly followed Wylleman and Lavallee's (2004) holistic approach and examined athletes' transitions in nonsport areas, alongside athletic changes (see, e.g., Debois, Ledon, \& Wylleman, in press; Ryba, Stambulova, Ronkainen, Bundgaard, \& Selänne, in press). Furthermore, a growing number of researchers (see, e.g., Morris, Tod, \& Oliver, 2014; Stambulova, Engström, Franck, Linnér, \& Lindahl, in press) are utilising career transition explanatory models to explain the factors that influence coping and the subsequent success of a transition. One such model is the athletic career transition model (Stambulova, 1997, 2003). Within the model, a

21 transition is depicted as a process comprising of an individual's effort to cope with a set of demands through the mobilization of internal (e.g., an athlete’s knowledge) and external (e.g., social support) resources. Hindering a successful transition are barriers (e.g., an athlete’s

24 lack of skills, interpersonal conflict). If an individual effectively overcomes the demands, then they are proposed to experience a successfully transition. Conversely, ineffective coping 
will lead to a crisis-transition and will require an intervention.

Despite the increase in transition literature and the development of potentially relevant conceptual models, Park, Lavallee, and Tod (2013) observed that relatively few studies conducted on athletes' transitions in the United Kingdom (UK) have employed a theoretical framework. Notable exceptions sampling university student-athletes are Aquilina (2013) and MacNamara \& Collins (2010). MacNamara and Collins (2010) used Wylleman and Lavallee’s (2004) developmental model to inform their interviews with elite British track athletes before and after their transition to university. Similarly, in her multinational study into the opportunities and constraints for dual role athletes, Aquilina (2013) used Wylleman and Lavallee’s (2004) model to inform the researcher's approach to the interview process. Within both studies, the challenges faced by dual role athletes (e.g., balancing academic, athletic, and social commitments) and the potential resources for managing these demands (e.g., motivation to fulfil potential) were identified. Sampling and reporting issues, however, limit the generalizability of both studies. To illustrate, MacNamara and Collins (2010) interviewed six athletes and triangulated their responses against those provided by significant others and a talent development manager. The study therefore provides a useful insight into the transitional experiences of British track athletes, but it does not encapsulate the experience of student-athletes from other sports at the various universities. Furthermore, although Aquilina (2013) achieved cross-cultural validity through triangulating British student-athletes' responses with individuals from France and Finland, the study is restricted since no information is provided about where the student-athletes were based or whether the opportunities afforded to them were typical across British universities.

The critique made of Aquilina's (2013) study is particularly salient to the understanding of British university student-athletes’ experiences because individuals’ experiences vary markedly depending on which university they attend. Although high 
1 academic standards are expected of students across all British universities, the assistance

2 student-athletes receive to maintain excellence in both academic and athletic domains will

3 vary based on the institution. To elaborate, in 2001, nine multi-sport high-performance

4 centers (HPCs) were established in the UK to support athletes' holistic development and a

5 number of these centers are located on university campuses (English Institute of Sport, 2015).

6 Elite student-athletes who enroll at these institutions are therefore more likely to have access

7 to support and provision (e.g., sport lifestyle advisors) than student-athletes are at other sites

8 (Aquilina \& Henry, 2010). Indeed, McKenna and Dunstan-Lewis (2004) identified a lack of

9 support and understanding as one of the three areas of concern for elite student-athletes at a

10 'traditional' British university (i.e., where courses include classics, law, medicine, and

11 science). However, to date, McKenna and Dunstan-Lewis' study represents the only investigation into the experiences of elite student-athletes at a specific British university and a lack of understanding therefore exists about student-athletes at other institutions. This lack

14 of knowledge is compounded by the low validity of drawing from literature on studentathletes in other nations. For example, despite a vast amount of literature existing on the experiences of student-athletes in the United States of America (USA), elite student-athletes in the USA more closely resemble professional sportspeople than students, and thus their experiences cannot be readily applied to their British counterparts who are required to demonstrate both academic and athletic excellence (Cross, 2004).

Accordingly, the purpose of the present study was to examine the transitional experiences of student-athletes based at British university housing a national HPC and offering elite sport support services. More specifically, the aim was to conduct a holistic exploration of the demands faced by student-athletes, the resources they had available for coping with these demands, the coping strategies implemented, and any barriers that inhibited their successful transition. Furthermore, it was hoped that the results from the study would 
1 inform future support and provision for elite student-athletes at the university.

2

\section{Design}

\section{The Case}

\section{Method}

To investigate the multifaceted transitional challenges faced by university studentathletes, a single instrumental case study design was used with the university representing the unit of analysis (Stake, 1995). This approach involved selecting a specific case (i.e., the university) and using multiple perspectives rooted within that context to explore and illustrate the problem of interest (Creswell, 2013; Lewis \& McNaughton Nicholls, 2014). To obtain these multiple perspectives, a combination of interviews and focus groups were conducted. Interviews were used with current and recently graduated student-athletes to allow their personal experiences of the transitions to be fully explored and their journey through university to be understood (Kvale \& Brinkmann, 2008). To provide further detail and create a holistic representation (cf. Lambert \& Loiselle, 2008), focus groups were then conducted with administrators, coaches, and support staff to enable their collective observations of the experiences of student-athletes to be captured. To direct the data interpretation, Wylleman and Lavallee’s (2004) developmental model of transitions faced by athletes and Stambulova's (2003) athletic career transition model were used.

A British university was purposively selected for this study based on the number of elite student-athletes at the institution, its record of sporting success, and its provision of elite athlete support. To elaborate, student-athletes at the university perform on a national or international level in 13 performance and development sports (i.e., sports receiving accessing to elite support services). In addition, the university acts as the base for athletes from four National Governing Bodies. In terms of sporting success, over 90 athletes with relations to the university competed in the London 2012 Olympic and Paralympic Games, and 35 current 
1 and ex student-athletes won medals at the 2014 Commonwealth Games in Glasgow (LLoyd,

2 2014). The university has also won the British Universities and Colleges Sport

3 Championships for 34 consecutive years (BUCS, 2014). Elite athletes studying at the

4 university have access to sports science and medicine (e.g., fitness testing, physiotherapy)

5 services (Sport Development Centre, 2015). Furthermore, student-athletes receive academic

6 support from an education and development manager, lifestyle support from performance

7 sport mentors, and the most talented performers also receive financial support.

8 Participants

Participants were recruited based on their current or previous experience of studentathletes' transitions at the case university. In total, 26 individuals (6 current student-athletes,

113 recently graduated student-athletes, 9 coaches, 3 support staff, and 5 administrators) were included in the sample. Descriptive information for the current and recently graduated student-athletes is provided in Table 1. Recently graduated student-athletes had completed

14 their university studies one year prior to the interview and were currently still participating in elite sport. Nine of the current coaches at the university chose to participate in the focus

16 groups and represented a range of sports including cricket, field hockey, rugby union, swimming, and track and field. Coaching experience at the case university ranged from one year to 18 years. The support staff were one physiotherapist and two strength and conditioning coaches, and their experience working with university sports ranged from four years to 10 years. Administrative staff held a variety of roles (e.g., performance sport

21 strategic manager, sports scholarship scheme manager) and their experience working in university sport ranging between two and 12 years.

\section{Interview Guide and Questioning Route}

An interview guide and a questioning route were developed for the interviews and 25 focus groups, respectively. The interview guide was divided into five sections. The first 
1 section informed participants about the nature of the study, its purpose, participant right of

2 voluntary withdrawal, the treatment of data, and the precautions taken to ensure

3 confidentiality and participant anonymity. The second section provided a consent form that

4 allowed participants to indicate that they had fully understood the details of the project and to

5 ask any remaining questions. The interview began in earnest at the beginning of the third

6 section of the interview guide where participants were asked to provide relevant contextual

7 information (e.g., their age, their time participating in sport). Following the completion of

8 this part of the interview, student-athletes were asked to draw a timeline of their journey

9 through university sport mapping particular challenges and successes they had experienced.

10 Once completed, the diagram acted as a prompt for participant recall and it provided specific

11 events for the interview to explore. Section four comprised the main part of the interview

12 and asked questions about the challenges faced by student-athletes during university, the

13 necessary skills, attitudes, and values individuals needed to develop to cope with them, and

14 the barriers they encountered. An example question is "what skills, attitudes, and values do

15 student-athletes need to develop whilst they are at university?” The fifth section concluded

16 the interview by encouraging participants to share any thoughts about their interview experience. Although the interview guide was semi-structured and the order of the sections remained constant across interviews, the order of the questions asked within each section varied in accordance with the flow of the conversation.

A questioning route was developed to guide the focus groups conducted with the

21 administrators, coaches, and support staff; it comprised the same five main sections as the interview guide. The first and second sections provided detailed information about the study

23 and the opportunity for the participants to provide informed consent. The third section

24 invited participants to introduce themselves to the other members of the focus group by

25 providing their name and detailing their involvement in university sport, and to discuss an 
opening topic (viz. the benefits and consequences for student-athletes participating in university sport). The fourth section comprised questions that were designed to elicit discussion about the challenges they had observed student-athletes encountering, the resources they felt student-athletes should develop, and any strategies they had implemented in an attempt to support the student-athletes. The fifth section concluded the focus group by encouraging the participants to share any thoughts about their focus group experience.

\section{Procedure}

Following institutional ethical approval, enquiries were made via email to the elite sport squads at the university, and to all of the university’s administrators, coaches, and support staff. Recently graduated student-athletes were contacted via email using the contact details they had voluntarily provided in a database before they left the institution. For those who were willing to take part, a mutually convenient time and location was arranged. In total, ten semi-structured interviews ${ }^{2}$ and five focus groups took place. Interviews were conducted either face-to-face or over Skype ${ }^{\mathrm{TM}}$. To ensure that participants' responses were accurately represented in the final data set, all interviews were digitally recorded. The interviews lasted between 48 and 74 minutes and, following transcription, yielded 152 pages of single-line spaced text. All of the participants were given pseudonyms to protect their identity and ensure their anonymity.

Focus groups were clustered according to participants' roles (i.e., there were three focus groups with coaches, one with support staff, and one with administrators). The first author acted as the facilitator for the focus groups and each group contained between three or four participants to allow adequate speaking time for each participant and to encourage effective interaction and exchange of views (Krueger \& Casey, 2009; Stewart, Shamdasani,

\footnotetext{
${ }^{2}$ In addition to the interviews conducted with student-athletes, an interview was took place with one administrator. This decision was made to alleviate any hierarchical issues that may have resulted from his senior role and potentially restricted participant disclosure (cf. Hollander, 2004); head and assistant coaches from the same sport were also separated in the focus groups for this reason.
} 
1 \& Rook, 2007). The five focus groups ranged in duration from 49 to 84 minutes and the

2 audio recordings were transcribed verbatim yielding 96 pages of single-line spaced text.

\section{Data Analysis}

The transcripts from the one-to-one interviews and focus groups were analyzed together to enhance data completeness on the topic of student-athletes' transitional experiences at the case university (cf. Lambert \& Loiselle, 2008). Focus groups were thus analyzed using whole group analysis so that each group became a comparable unit of analysis to each of the individual interviews (Wilkinson, 2011). The first author analyzed the transcripts using the guidelines from framework analysis presented in Spencer, Ritchie, Ormston, O’Connor, and Barnard (2014; see also, Pope, Ziebland, \& Mays, 2000). First, transcript were read several times to ensure familiarization and then pertinent themes emerging from the data were generated. Second, demand themes were structured according to Wylleman and Lavallee’s (2004) model and resource, barrier, and coping themes associated with each demand where then structured according to Stambulova's (2003) model. Third, data contained within each theme was reviewed to ensure that they had been collated coherently and that no themes were missing from the framework. To further support this stage of the analysis, two validation procedures were implemented. The first procedure involved the second author independently reviewed the accuracy of the thematic framework to the data. For the second procedure, an independent researcher (external to the research team) reviewed a sample of raw data quotes (33\%) and attempted to match them to the themes generated. Although the clustering of the quotes to themes reached a satisfactory level of agreement (97.3\%), some of the themes were relabeled to better encapsulate the raw data (e.g., high performance level was changed to continued increase in performance level; increasing communication was changed to communicating with staff). The resultant thematic framework is presented in Table 2. Finally, member validation was employed to ensure that 
1 the interpretation of the data by the researchers represented the meaning initially intended by

2 the participants (Lewis, Ritchie, Ormston, \& Morrell, 2014).

\section{Results}

Constructed from the experiences of current student-athletes and supported by the experiences of recently graduated student-athletes and university staff, the results from this qualitative investigation depict the transitions encountered by dual role athletes at the case university. The thematic framework resulting from the analysis, and the relationships between demands, resources, barriers, and coping, are shown in Table 2. In total, 14 transitional demand themes were identified across the four levels (i.e., athletic, academic/vocational, psychological, psychosocial) from 99 raw data quotes. Fourteen personal (100 raw quotes) and 13 external (153 raw quotes) resource themes were identified; ten external barrier themes (35 raw quotes) were also found ${ }^{3}$. Furthermore, participants described nine coping strategy themes (91 raw quotes). Below, a selection of extracts are presented as illustrative examples of the demands faced by student-athletes at the case university, the internal and external resources they have to deal with these demands, the external barriers they may encounter, and the coping strategies they may implement.

\section{Athletic Level Transitions}

When arriving at the case university, student-athletes experienced two athletic transitional demands: competition for selection and training and lifestyle expectations. In relation to the latter, one student-athlete spoke of struggling to meet the elevated training requirements of university sport: “At the start of the year, I found it really hard to adapt to everything, because I was used to training only 3, 4 times a week, and now I train 10 times a week”. Evidence for this athletic level demand was also provided by the experiences of a

\footnotetext{
${ }^{3}$ Within the data, all of the described personal barrier themes were experienced in relation to, or following, an external barrier theme (e.g., misperceptions of ability following experience of a national talent program). Therefore, external factors were the origins of these barriers and are presented instead of personal variables.
} 
1 recently graduated student-athlete and various university staff. Within the administrator

2 focus group, for example, one individual stated:

I do think there are some people who are still not prepared for what we need them to do when they come here. So some of them who've got by on talent and a couple of training sessions a week ... come here, and they're expected to train at least once, sometimes twice a day, you can’t go out drinking, you can’t do this, you can’t do that, and it's a big step up.

To cope with these transitional demands, participants spoke of the impact that existing student-athletes at the university had. For example, one of the current student-athlete described how he tried to support new student-athletes meet their sports expectations: I just try and be a good example and help the Freshers out . . . you've got to help people to not make the same mistakes that you did, and just be a good role model as the old guy.

Furthermore, support staff noted the importance of elite role model peers within the university environment for setting the standard expected and for inspiring new studentathletes to reach this level:

Role models will determine the culture of an environment and putting young, easily influenced people into a setting where they have a carrot dangled in front of them, will lead them to interpret what has been set as the standards and culture of that club. This process of observational learning described by the staff was evident in both the current and recently graduated student-athletes’ responses. For example, one recently graduated student-athlete described how she learnt from the international athletes training at the case university:

Once I realized that [being an international swimmer] was what I really wanted, I started looking at the way that the other people at the ITC [Intensive Training Centre] 
conducted themselves and there was no excuses. There's a reason that they're the best, and I needed to behave like them if I wanted to be the best.

However, staff at the case university also discussed how student-athletes’ attempts to overcome the demands they encounter as part of their initial transition into university sport, and throughout their time at university (e.g., continued increase in performance level, injury and fitness issues, performance setbacks), were hindered by various external barriers. More specifically, staff noted that the societal celebrity culture combined with experience on talent identification (ID) programs, resulted in some student-athletes holding misperceptions about their ability and lacking the necessary work ethic to overcome these sporting demands. The administrator quote below elucidates the impact of talent ID programs: The proliferation of world class performance programs and the fact that these kids have practiced in a national under-14 program, under-16 program, under-18 program; they are probably privileged beyond their talent too early. And therefore they sometimes get minor delusions of grandeur before they have actually earned the privilege of getting the support that we can offer them. And I do have a real concern that too many kids who are highly talented, but just don’t have the work ethic. And they still arrive to us at age 18 with an expectation that we're just going to keep supporting them whatever.

\section{Academic/Vocational Level Transitions}

During their time at the case university, the student-athletes experienced academic transitional demands when meeting the requirements of their university degree and when preparing for a post-university career. In relation to the transitional demands of embarking on a degree, one student-athlete spoke of her teammate's struggle to meet the extensive commitments of her Masters degree in Sport Science:

She's so busy and she's struggling to come to training, it seems like such a nightmare 

... she just lived in the library and was always in labs ... I don't know if I could have looked forward to playing hockey at the end of the day if I had 9-5 like she did. Recently graduated student-athletes and staff also acknowledged the difficulties experienced by student-athletes when attempting to meet the demands of a degree program, as the following quote from a recently graduated student-athlete illustrates: My dissertation supervisor wanted me to start collecting data right at the end of October, the start of the Masters year ... so it meant that as soon as the hockey season started, I had to start my dissertation as well so it was a lot harder to manage it. To support student-athletes overcome these academic demands, the case university provides a variety of academic processes (e.g., academic flexibility, progress reports), perceived by the participants to make it unique from any other British universities. For example, one current student-athlete described how the case university was, to his knowledge, "the only university that lets you do a stretch degree”, which enabled him to split his final year of study over two years. Furthermore, one student-athlete described how academic flexibility enabled him to attend international competitions without missing class: If we have an international competition we'll fly out on the Thursday so generally I'll miss from midday Thursday or sometimes all day and Friday, but the department have been quite flexible. If I've needed to change a lab group or anything like that, I’ve been able to.

Within his interview, the administrator also espoused the uniqueness of provision at the case university, as the following extract illustrates: We have, I think, support systems that are way ahead of almost any other university in the UK. To actually have formal university policy that's been through Senate which outlines how academic flexibility will work with elite student-athletes, how stretch degrees work ... I would guarantee there is no other university in this county that has 
got that level of policy written into the university structure.

Some of the systems put in place at the case university, however, were not perceived as positively. To elaborate, the case university has an affiliation with a local further education college. The college provides elite student-athletes, who fail to achieve the necessary grades to attend the university, an alternative setting to continue their study whilst benefiting from the support provision at the university. Although this partnership has increased the number of athletes available for selection, the coaches noted that it has also created discontinuity in the course expectations and challenges faced by the student-athletes: With the college on board, we have more athletes that go to the college and the majority of athletes that are struggling are at the college ... I think the problem is that the college kids see what the uni kids do and they think they can do exactly the same. To cope with the academic demands they encounter and to utilize the flexibility in place, participants described how student-athletes were, or needed to be, proactive and plan ahead. One student-athlete spoke about meeting with their academic personal tutor to organize their potentially stressful exam period: I went to see him [personal tutor] to sort it [missing an exam] out and find out what I could do about it. Obviously this may happen again in the summer and it's a big time for me, that's when there's potentially international races and there could be an issue in managing to do the exam and all my other things as well.

\section{Psychological Level Transitions}

Psychological transitional demands for student-athletes encapsulated the movement from adolescence to adulthood including developing identity, establishing personal motivation, learning to look after oneself, and taking personal responsibility for one's development. For example, one student-athlete spoke about how he had become more willing to take responsibility for his training since being at university: 
I think that now I've come to university I feel more independent. I think it relates to the sport as well. So now I'm prepared to take training into my own hands and try and make it better myself rather than just taking orders from a coach. Within the coaches’ focus groups, it was evident that this transition towards personal responsibility occurred gradually during a student-athlete’s experience at university: I just see them accepting far more responsibility over their actions, and their directions, and their lives really ... And it’s just a gradual process of seeing them start to take ownership of their lives a little bit more. Coaches were perceived to have an active role in student-athletes' development of personal responsibility. Coaching staff described, for example, how they "try and throw them [the players] a lot of responsibility, so they will lead match-day debriefs and stuff like that”. However, coaches were also mindful and hesitant of always providing proactive support to student-athletes without them initially seeking help, as the following quote illustrates: I was wondering what [coach’s name] said [about making student-athletes aware of the processes]. If we put interventions in place, well preventions I guess, how much do they [the student-athletes] then just think that is the normal standard, and that is what they should expect every time they've given up. Does that actually solve them being proactive and doing it for themselves? Parents, on the other hand, were perceived to make this transition in personal responsibility more difficult for student-athletes by having taken responsibility for large amounts of the student-athletes' lives prior to university. For example, a recently graduated student-athlete stated that living at home prior to university meant that parents “did everything for you”. This assertion was reinforced by members of the administrator focus group who described how support from parents and schools, prior to university, left many student-athletes without the ability to look after themselves or take responsibility: 
People regularly tell me we get athletes in here now who’ve been molly-cuddled, up until the point of 18, and they come here and they can't even make a sandwich or wash their clothes, because their parents or their schools have done it all for them. One of the methods that participants believed student-athletes could use to cope with the demands associated with taking personal responsibility was to display openness for learning and challenge. The desire for learning was also perceived to be important for student-athletes reaching a higher athletic standard, as the following extract illustrates: I think the ones who perform best are the ones who are open-minded, inquisitive, curious, who want to know and understand what is happening to them. The ones who are more 'coach tell me if I need to go left or right', will get to certain point, but will probably not make it to the next step. So there is a degree of desire to learn that has to be there in the individual.

\section{Psychosocial Level Transitions}

On a psychosocial level, student-athletes were described as experiencing a change in coach, a decrease in parental support, and the need to establish new friendships when starting at university. In addition, these psychosocial demands continued throughout student-athletes' time at university as they were required to balance and manage their relationships. Studentathletes' experiences of changing their coach varied among participants. For example, some established an immediate rapport with their new coach and were complimentary of them: "he [the coach] is like my mentor as well as my coach" and "he [the coach] was the most knowledgeable person that I have had by miles”. However, others experienced difficulty initially bonding with their new coach: "I think the coach thought I had a bit of an attitude, or thought I was a bit of a pisshead, or didn’t think I was focused regarding my hockey”.

Furthermore, the coach-athlete relationship was perceived to fluctuate through university.

One current-student athlete, for example, described how the relationship changed after their 
1 first year at the university: "after the first year, I knew the coach quite well and I got on with

2 him so, there's a bit more of a bond, we know each other quite well and I'm quite happy to

3 discuss things”. A recently graduated student-athlete described how his challenging coach-

4 athlete relationship, ultimately had a positive impact on his hockey:

I thought he [the coach] was one of the best coaches I've had in that he showed me it is not easy to succeed, you have to push yourself and I'm not going to lie, if I hadn't gone to [the case university], if I hadn't been coached by him, I wouldn't be the player I am today. That's not to say there weren't times you hated him, but that's the same with every coach, you hate them at times, but you actually think they're class. One of the strategies that was described by the participants to help them understand the requirements of their new coach was to increase communication with the staff member. In this instance, a recently graduated student-athlete outlined how he felt greater communication with a coach or experienced student-athlete teammates could help alleviate this transitional demand:

There needed to be more communication. Be that sitting down [with the coach], or even some of the older members of squad sitting down all of the freshers [first year students] and explaining 'each and every one of us has had different experiences regarding our first year, but this is what is expected of you in your first few weeks, then next few weeks, then next few weeks'. In addition, coaches described how a student-athlete's ability to effectively communicate and act with integrity were important for establishing a coach-athlete relationship. For example, within one of the coaches’ focus groups, participants described how athletes needed to be "comfortable in picking a phone up, or letting people know where they are, what's going on in their family” if they required support. Integrity and emotional intelligence were highlighted in another coach focus group, as the following quote illustrates: 
To have that little bit of emotional intelligence to realize what their values are and show good integrity towards those ... they [individuals who do this] ultimately last really well and make the most of everything in the program. They connect really well with their peers and staff and everyone around them.

One of the barriers faced when establishing a relationship with a new coach for teamsport athletes at the case university, was the lack of flexibility in who their coach would be.

This meant that student-athletes in team-sports were required to try and build these relationships, whereas individual-sport athletes were able to change. The following extract from the support staff focus group illustrates this dynamic:

The other thing slightly different is that in the [individual-sport] disciplines, if you don't have synergy with the coach you can go and get a different coach. Whereas if you don’t have synergy with the [team-sport] coach and you're a [team-sport] player then there is no other option there. So with regard to role models and personal development, and the mentoring and pastoral support coaches and support staff are giving, in some scenarios there is slightly more flexibility.

\section{Discussion}

The current study explored the transitional experiences of student-athletes based at British university housing a national HPC and offering elite sport support services. An indepth understanding of these transitions was developed through analysis of qualitative data collected with student-athletes studying at the university, athletes who have recently graduated from the institution, and the university staff (e.g., coaches) who aim to support athletes during these years. The results from the study demonstrate that student-athletes experienced simultaneous transitions in athletic (e.g., training and lifestyle expectations), academic (e.g., course requirements), psychological (e.g., taking personal responsibility), and psychosocial (e.g., change in coach) development. Furthermore, participants reported a 
1 variety of personal (e.g., dedication and strong work ethic, self-discipline) and external (e.g.,

2 academic flexibility, elite role model peers) resources that help student-athletes cope with the

3 transitional demands. Coping strategies implemented by student-athletes included

4 communicating with staff, observational learning of through their peers, and setting goals. A

5 range of external barriers (e.g., parental overprotection, society and celebrity culture)

6 hindering student-athletes’ transitions were also described.

The identification of multifaceted transitional experiences by the participants in the

8 current study supports extant research into the simultaneous development proposed to occur

9 in athletes between the ages of 18 and 21 years (see, e.g., Knowles \& Lorimer, 2014; Miller

10 \& Kerr, 2002). For example, current student-athletes, recently graduated student-athletes,

11 and staff reported a psychological development in student-athletes level of personal responsibility and this shift was likely to be related to the concurrent psychosocial transition of decreasing parental support. The transitions experienced by student-athletes at the case university in the current study also support those previously identified in British track athletes commencing university (see, MacNamara \& Collins, 2010). Both studies identified higher standards of training and a change in coach as significant transitions, for example. However, the current study also advances the previous work of MacNamara and Collins (2010) because it investigated student-athletes’ transitions throughout their university study (e.g., postuniversity career), rather than solely focusing on the immediate experiences at the start of university. The transitions described in the current study are also comparable to those found

21 in non-student British athletes at this age (see, e.g., Finn \& McKenna, 2010) and university student-athletes from other nations (see, e.g., Falls \& Wilson, 2013).

The current study drew on Stambulova's $(1997,2003)$ athlete career transition model to explore the factors which affected the success of student-athletes' transitions at the case university. When reflecting on the support provided to student-athletes at the institution, 
1 participants acknowledged the uniqueness of provision compared to other British universities.

2 For example, the case university has formal legislation detailing how elite athletes can

3 receive special dispensation if academic and athletic commitments clash and if they want to

4 extend their studies for an additional year. Furthermore, the existence of a national HPC on-

5 site meant that elite student-athletes had access to an array of medical and sport science

6 support. This provision is in stark contrast to that described previously by McKenna and

7 Dunstan-Lewis (2004) at a 'traditional' British university. Indeed, the challenges (e.g.,

8 relationships with academia, lack of support and understanding) described in McKenna and

9 Dunstan-Lewis' study were not evident in the current study, with academic staff and a high

10 quality academic course, instead, perceived as resources for overcoming transitional demands. This latter observation on the benefit of study alongside sport is in accordance with that previously found in British, Finnish, and French university student-athletes by Aquilina (2013); it does, however, contrast with findings previously reported on the perceptions of

14 Australian student-athletes (see, Cosh \& Tully, 2014) and Swedish adolescent studentathletes (see, Stambulova et al., in press). One explanation for the difference found between student-athletes’ perceptions in the current study and those in Cosh and Tully's (2014) study, for example, may be that the increased support for academic studies provided at the case university transforms the course from a chore to a welcome distraction. However, irrespectively of the support on offer, participants in the current study also emphasized how student-athletes still needed to possess and display a desire for learning, which, as described below, was not the case for all individuals at the case university. Participants perceived student-athletes encountered a range of external barriers that

23 subsequently resulted in personal deficiencies. To illustrate, prior experience of junior 24 performance programs, professional academies, or National Lottery funding was thought to result in a lack of work ethic and a climate of expectancy. Staff, for example, suggested that 
1 some elite student-athletes arrived at the university with "minor delusions of grandeur".

2 Furthermore, coaching staff debated the merits of providing proactive support as opposed to

3 allowing the student-athletes to learn from their own mistakes. Within the UK, such a debate

4 would be uncommon at the majority of universities because academic and athletic

5 departments operate independently and student-athletes are given personal agency over

6 ensuring they meet the expectations placed on them. These discussions therefore represent a

7 novel finding in the literature on university student-athletes' transitions; however they do

8 concur with the emerging talent development literature which opposes overtly supportive

9 programs, in favor of those which involve challenge and coping (see, e.g., Collins \&

10 MacNamara, 2012; Howells \& Fletcher, 2015; Sarkar, Fletcher, \& Brown, in press). This

11 finding therefore has potentially significant implications for practitioners and policy makers

12 as it questions whether existing support practices are actually having the desired long-term

13 effects on athletes’ development.

14 The participants in the current study described a range of coping strategies that

15 student-athletes implemented to overcome the transitional demands they experienced. Whilst

16 MacNamara and Collins (2010) have previously highlighted the use of goal setting, the

17 remainder of the coping strategies identified represent new findings in British university

18 student-athletes. For example, student-athlete participants described how they overcame the

19 psychosocial transition of changing coach by approaching them prior attending university and

20 ensuring that they maintained communication with them. Furthermore, social agents were

21 found to be an important source of support, encouragement, and escape, and peers were a source of observational learning and social comparison to help student-athletes achieve excellence in both their sport, and their studies. The impact of social agents observed in the

24 current study supports a recent exploration of the transitional experiences of Australian university student-athletes (see, Cosh \& Tully, in press) and elite dual career athletes (see, 
1 Debois et al., in press), within which participants reported seeking social support from either

2 their coach or parent to overcome demands.

The findings of the current study have a range of practical implications for how universities can facilitate student-athletes' coping with the transitions they experience. First, participants suggested that student-athletes would benefit from arriving at university with an awareness of the requirements to be placed on them. To support this, greater communication between coach and incoming student-athlete should be implemented. Additionally, studentathletes suggested that they would have benefitted from having more experienced studentathletes sharing their first-year experiences. Second, the case university has successfully implemented a system of academic flexibility and communication between academic and athletic departments that is unique in the UK; other universities should explore how they can enhance dialogue within their institutions to provide greater support to their elite studentathletes. Third, whilst student-athletes were described as needing to be proactive in seeking support and in learning how to take personal responsibility over their development, coaches can also play a significant role in creating opportunities for student-athletes to overcome these psychological demands. For example, coaches could give student-athletes responsibility for establishing team ethos and for determining squad discipline, as this would teach them that they are accountable for their own actions. The suggestions listed here, however, give rise to an important debate regarding whether university level student-athletes benefit most from proactive support or experiential learning. To elaborate, some of the participants encouraged the use of support strategies (e.g., academic flexibility) to help student-athletes cope with their holistic transitions. However, this contradicted the view held by others who were critical of the increasing support athletes received prior to university (e.g., talent programs). To resolve this debate, it is likely that institutions will need to establish a balance between support and independence, perhaps in part graded by the student- 
1 athletes' year of study as they grow and increase their level of personal responsibility.

3 British universities which has been limited to the experience of a specific transition by British

4 track athletes (see, MacNamara \& Collins, 2010), student-athlete experiences at a traditional

5 British university (see, McKenna \& Dunstan-Lewis, 2004), and a general account of student-

6 athlete experiences (see, Aquilina, 2013). Furthermore, a notable strength of this study is the

7 recruitment of participants from a range of roles associated with student-athletes (e.g.,

8 administrators, coaches), in addition to the student-athletes themselves, as this provides

9 multiple perspectives that hopefully engender a holistic and comprehensive examination of

10 the student-athlete experience (cf. Johnston, Harwood, \& Minniti, 2013; Jones, Dunn, Holt,

11 Sullivan, \& Bloom, 2011). A limitation of the current study was the lack of representation

12 from academic staff. The decision not to recruit academic staff was made because it was

13 anticipated that any one staff member would have had only sporadic experience of transitions

14 in student-athletes. However, notwithstanding this justification, the results from this study

15 suggest that academic staff play an active role in shaping the development of student-athletes

16 and future research would benefit from obtaining their perspectives and understanding of how

17 academic and athletic departments can work in collaboration for the benefit of the students.

18 A further limitation of the current study is the use of a case study methodology since this

19 precludes comparison between the experiences of student-athletes at the case university and

20 those in other settings. Future research should compare the experiences of student-athletes

21 across a variety of British universities, in addition to conducting a cross-cultural exploration

22 of university student-athletes' experiences in North America, Europe, and the rest of the

23 world. 
3 Sport Development Centre and the Talented Athlete Scholarship Scheme (TASS). We thank

4 Colin Allen and James Farndon for their discussions about performance lifestyle. We would

5 also like to thank Mustafa Sarkar for independently reviewing our raw data quotes and

6 themes in the data analysis. 
References

2 Ahlgren-Bedics, R., \& Monda, S. (2009). Life skills for collegiate student-athletes: Defining the need and model practices. In E. F. Etzel (Ed.), Counseling and psychological services for college student-athletes (pp. 113-142). Morgantown, WV: Fitness Information Technology.

Aquilina, D. (2013). A study of the relationship between elite athletes' educational development and sporting performance. The International Journal of the History of Sport, 30, 374-392. doi:10.1080/09523367.2013.765723

Aquilina, D., \& Henry, I. (2010). Elite athletes and university education in Europe: A review of policy and practice in higher education in the European Union Member States. International Journal of Sport Policy and Politics, 2, 25-47. doi:10.1080/19406941003634024

Bennie, A., \& O'Connor, D. (2006). Athletic transition: An investigation of elite track and field participation in the post-high school years. Changes: Transformations in Education, 9, 59-68.

Blinde, E. M., \& Greendorfer, S. L. (1992). Conflict and the college sport experience of women athletes. Women's Sports and Physical Activity Journal, 1, 97-113.

British Universities \& Colleges Sport. (2012). Placing higher education in the performance pathway. London, UK: British Universities \& Colleges Sport.

British Universities \& Colleges Sport. (2014). BUCS points. Retrieved February 16, 2015, from http://www.bucs.org.uk/bucscore/bucspoints.aspx

Bruner, M. W., Munroe-Chandler, K. J., \& Spink, K. S. (2008). Entry into elite sport: A preliminary investigation into the transition experiences of rookie athletes. Journal of Applied Sport Psychology, 20, 236-252. doi:10.1080/10413200701867745

Coakley, J. (1993). Social dimension of intensive training and participation in youth sports. 
In B. R. Cahill \& A. J. Pearl (Eds.), Intensive participation in children's sport (pp. 77-94. Champaign, IL: Human Kinetics.

Collins, D., \& MacNamara, Á. (2012). The rocky road to the top: Why talent needs trauma. Sports Medicine, 42, 907-914. doi:10.1007/BF03262302

Cosh, S., \& Tully, P. J. (2014). “All I have to do is pass”: A discursive analysis of student athletes' talk about prioritising sport to the detriment of education to overcome stressors encountered in combining elite sport and tertiary education. Psychology of Sport and Exercise, 15, 180-189. doi:10.1016/j.psychsport.2013.10.015

Cosh, S., \& Tully, P. J. (in press). Stressors, coping and support mechanisms for studentathletes combining elite sport and tertiary education: Implications for practice. The Sport Psychologist. doi:10.1123/tsp.2014-0102

Creswell, J. W. (2013). Qualitative inquiry \& research design. Thousand Oaks, CA: Sage.

Cross, J. A. (2004). The British student-athlete experience: Identity, commitment and role conflict. (Doctoral dissertation). Retrieved from http://dspace.lboro.ac.uk/2134/7610

Debois, N., Ledon, A., \& Wylleman, P. (in press). A lifespan perspective on the dual career of elite male athletes. Psychology of Sport and Exercise. doi:10.1016/j.psychsport.2014.07.011

Desprez, B., Chaudel, V., Fernandez-Gabaldon, N., Hilbrandt, F., Routil, J., Paez, L., . . Pontacq, T. (2008). Study on training of young sportsmen/women in Europe. Brussels, Belgium: European Commission.

English Institute of Sport. (2015). Our sites. Retrieved February 16, 2015, from http://www.eis2win.co.uk/Pages/About_EIS_Our_Sites.aspx

Falls, D., \& Wilson, B. (2013). 'Reflexive modernity’ and the transition experiences of university athletes. International Review for the Sociology of Sport, 48, 572-593. doi:10.1177/1012690212445014 
1 Ferrante, A. P., \& Etzel, E. F. (2009). College student-athletes and counseling services in the new millennium. In E. F. Etzel (Ed.), Counseling and psychological services for college student-athletes (pp. 1-49). Morgantown, WV: Fitness Information Technology.

Finn, J., \& McKenna, J. (2010). Coping with academy-to-first-team transitions in elite English male team sports: The coaches' perspective. International Journal of Sports Science and Coaching, 5, 257-279. doi:10.1260/1747-9541.5.2.257

Greendorfer, S. L. \& Blinde, E. M. (1985). “Retirement” from intercollegiate sport: Theoretical and empirical consideration. Sociology of Sport Journal, 2, 101-110.

Haley, M., \& Saghafi, T. (2012). Legacy live. London, UK: Podium.

Hollander, J. A. (2004). The social contexts of focus groups. Journal of Contemporary Ethnography, 33, 602-637. doi:10.1177/0891241604266988

Hollings, S., Mallett, C., \& Hume, P. (2014). The transition from elite junior track-and-field athlete to successful senior athlete: Why some do, why others don't. International Journal of Sports Science and Coaching, 9, 457-472. doi:10.1260/1747-9541.9.3.457

Howells, K., \& Fletcher, D. (2015). Sink or swim: Adversity- and growth-related experiences in Olympic swimming champions. Psychology of Sport and Exercise, 16, 37-48. doi:10.1016/j.psychsport.2014.08.004

Kimball, A. C., \& Freysinger, V. (2003). Leisure, stress, and coping: The sport participation of collegiate student-athletes. Leisure Sciences, 25, 115-141. doi:10.1080/01490400306569

Knowles, A. M., \& Lorimer, R. (2014). A case study of an athlete's experience of multiple change-events moving between team and individual sports. Journal of Applied Sport Psychology, 26, 197-210. doi:10.1080/10413200.2013.819393

Krueger, R. A., \& Casey, M. A. (2009). Focus groups: A practical guide for applied research 
(4th ed.). Thousand Oaks, CA: Sage.

2 Kvale, S., \& Brinkmann, S. (2008). Interviews: Learning the craft of qualitative research (2nd ed.). Thousand Oaks, CA: Sage.

Lambert, S. D., \& Loiselle, C. G. (2008). Combining individual interviews and focus groups to enhance data richness. Journal of Advanced Nursing, 62, 228-237. doi:10.1111/j.1365-2648.2007.04559.x

Lewis, J., \& McNaughton Nicholls, C. (2014). Design issues. In J. Ritchie, J. Lewis, C. McNaughton Nicholls, \& R. Ormston (Eds.), Qualitative research practice: A guide for social science students and researchers (pp. 47-76). London, UK: Sage.

Lewis, J., Ritchie, J., Ormston, R., \& Morrell, G. (2014). Generalising from qualitative research. In J. Ritchie, J. Lewis, C. McNaughton Nicholls, \& R. Ormston (Eds.), Qualitative research practice: A guide for social science students and researchers (pp. 347-366). London, UK: Sage.

Lowe, H., \& Cook, A. (2003). Mind the gap: Are students prepared for higher education? Journal of Further and Higher Education, 27, 53-76. doi:10.1080/03098770305629

LLoyd, S. (2014). About us. Retrieved February 19, 2015, from http://loughboroughsport.com/athletic-union/about-us/

MacNamara, Á., \& Collins, D. (2010). The role of psychological characteristics in managing the transition to university. Psychology of Sport and Exercise, 11, 353-362. doi:10.1016/j.psychsport.2010.04.003

McKenna, J., \& Dunstan-Lewis, N. (2004). An action research approach to supporting elite student-athletes in higher education. European Physical Education Review, 10, 179198. doi:10.1177/1356336X04044070

Miller, P. S., \& Kerr, G. (2002). The athletic, academic and social experiences of intercollegiate student-athletes. Journal of Sport Behavior, 25, 346-367. 
1 Mills, A., Butt, J., Maynard, I., \& Harwood, C. (2012). Identifying factors perceived to influence the development of elite youth football academy players. Journal of Sports Sciences, 30, 1593-1604. doi:10.1080/02640414.2012.710753

Morris, R., Tod, D., \& Oliver, E. (2014). An analysis of organizational structure and transition outcomes in the youth-to-senior professional soccer transition. Journal of Applied Sport Psychology, 1-19. doi:10.1080/10413200.2014.980015

Park, S., Lavallee, D., \& Tod, D. (2013). Athletes' careers in the United Kingdom and the Republic of Ireland. In N. Stambulova \& T. V. Ryba (Eds.), Athletes' careers across cultures (pp. 209-221). East Sussex, UK: Routledge.

Pearson, R. E., \& Petitpas, A. J. (1990). Transitions of athletes: Developmental and preventive perspectives. Journal of Counseling \& Development, 69, 7-10. doi:10.1002/j.1556-6676.1990.tb01445.x

Petitpas, A. J., Brewer, B. W., \& Van Raalte, J. L. (2009). Transitions of the student-athlete: Theoretical, empirical, and practical perspectives. In E. F. Etzel (Ed.), Counseling and psychological services for college student-athletes (pp. 283-302). Morgantown, WV: Fitness Information Technology.

Podium, Universities UK, \& British Universities \& Colleges Sport. (2012). Olympic and Paralympic Games: The impact of universities. London, UK: Podium.

Pope, C., Ziebland, S., \& Mays, N. (2000). Analysing qualitative data. British Medical Journal, 320, 114-116.

Preece, A., Taylor, M., Calvey, C., Delany, H., Bertelli, M., Leake, G., . . . Aquilina, D. (2004). Education of young sportspersons. Brussels, Belgium: European Commission.

Pummell, B., Harwood, C., \& Lavallee, D. (2008). Jumping to the next level: A qualitative examination of within-career transition in adolescent event riders. Psychology of Sport and Exercise, 9, 427-447. doi:10.1016/j.psychsport.2007.07.004 
1 Ryba, T. V., Stambulova, N. B., Ronkainen, N. J., Bundgaard, J., \& Selänne, H. (in press). Dual career pathways of transnational athletes. Psychology of Sport and Exercise. doi:10.1016/j.psychsport.2014.06.002

Sarkar, M., Fletcher, D., \& Brown, D. J. (in press). What doesn’t kill me...: Adversity-related experiences are vital in the development of superior Olympic performance. Journal of Science and Medicine in Sport. doi:10.1016/j.jsams.2014.06.010

Shurts, W. M., \& Shoffner, M. F. (2004). Providing career counseling for collegiate studentathletes: A learning theory approach. Journal of Career Development, 31, 95-109. doi:10.1007/s10871-004-0567-4

Spencer, L., Ritchie, J., Ormston, R., O'Connor, W., \& Barnard, M. (2014). Analysis: Principles and processes. In J. Ritchie, J. Lewis, C. McNaughton Nicholls, \& R. Ormston (Eds.), Qualitative research practice: A guide for social science students and researchers (pp. 269-293). London, UK: Sage.

Sport Development Centre. (2015). Athlete support. Retrieved February 16, 2015, from http://loughboroughsport.com/athlete-support/

Stake, R. (1995). The art of case study research. Thousand Oaks, CA: Sage.

Stambulova, N. (1994). Developmental sports career investigations in Russia: A postperestroika analysis. The Sport Psychologist, 8, 221-237.

Stambulova, N. (1997). Sociological: Sports career transitions. Paper presented at the 2nd annual congress of the European College of Sport Science, Kopenhagen, Demark.

Stambulova, N. (2003). Symptoms of a crisis-transition: A grounded theory study. In N. Hassmen (Ed.), SIPF yearbook (pp. 97-109). Örebro, Sweden: Örebro University Press.

Stambulova, N., Alfermann, D., Statler, T., \& Côté, J. (2009). ISSP position stand: Career development and transitions of athletes. International Journal of Sport and Exercise 

Psychology, 7, 395-412. doi:10.1080/1612197X.2009.9671916

2 Stambulova, N., Franck, A., \& Weibull, F. (2012). Assessment of the transition from juniorto-senior sports in Swedish athletes. International Journal of Sport and Exercise Psychology, 10, 79-95. doi:10.1080/1612197X.2012.645136

Stambulova, N. B., Engström, C., Franck, A., Linnér, L., \& Lindahl, K. (in press). Searching for an optimal balance: Dual career experiences of Swedish adolescent athletes. Psychology of Sport and Exercise. doi:10.1016/j.psychsport.2014.08.009

Stewart, D. W., Shamdasani, P. N., \& Rook, D. W. (2007). Focus groups: Theory and practice. Thousand Oaks, CA: Sage.

Wilkinson, S. (2011). Analysing focus group data. In D. Silverman (Ed.), Qualitative research (pp. 168-184). London, UK: Sage.

Wylleman, P., \& Lavallee, D. (2004). A developmental perspective on transitions faced by athletes. In M. Weiss (Ed.), Developmental sport and exercise psychology: A lifespan perspective (pp. 507-527). Morgantown, WV: Fitness Information Technology.

Yeo, A., Legard, R., Keegan, J., Ward, K., McNaughton Nicholls, C., \& Lewis, J. (2014). Indepth interviews. In J. Ritchie, J. Lewis, C. McNaughton Nicholls, \& R. Ormston (Eds.), Qualitative research practice: A guide for social science students and researchers (pp. 177-210). London, UK: Sage. 
1 Table 1

2 Current and Recently Graduated Student-Athletes' Descriptive Information

\begin{tabular}{llllll}
\hline Participant & Gender & Age & Year of study & Sport & Current sport level \\
\hline SA1 & F & 18 & $1^{\text {st }}$ & Track and field & Junior national champion \\
SA2 & M & 20 & $1^{\text {st }}$ & Rugby union & University $1^{\text {st }}$ XV \\
SA3 & M & 19 & $1^{\text {st }}$ & Triathlon & National series \\
SA4 & M & 20 & $2^{\text {nd }}$ & Badminton & International \\
SA5 & M & 22 & $5^{\text {th }}($ Final) & Triathlon & World champion \\
SA6 & F & 21 & $3^{\text {rd }}($ Final) & Field hockey & University $1^{\text {st }}$ XI \\
AL1 & M & 22 & & Field hockey & International \\
AL2 & F & 23 & & Swimming & International \\
AL3 & F & 26 & & Field hockey & National league \\
\hline
\end{tabular}

3 Note. $\mathrm{SA}=$ student-athlete; $\mathrm{AL}=$ recently graduated student-athlete; $\mathrm{F}=$ female; $\mathrm{M}=$ male 
Table 2

2 The Demands and Related Resources, Barriers, and Coping Strategies Observed in Student-Athletes' Transitions at the Case University

\begin{tabular}{|c|c|c|c|}
\hline Transitional demand & Resources utilized & Barriers encountered & Coping strategies implemented \\
\hline \multicolumn{4}{|l|}{ Athletic level } \\
\hline \multirow{7}{*}{$\begin{array}{l}\text { Competition for } \\
\text { selection (10) }\end{array}$} & Internal & & Being proactive and planning \\
\hline & Dedication and strong work ethic (1) & & ahead (1) \\
\hline & Desire for and openness to learning & & Observational learning and social \\
\hline & and challenge (1) & & comparison (1) \\
\hline & Resilience (3) & & Quitting (2) \\
\hline & Self-awareness (3) & & Seeking social support (1) \\
\hline & & $\begin{array}{l}\text { External } \\
\text { Overly competitive and intimidating } \\
\text { teammates (2) }\end{array}$ & \\
\hline \multirow{12}{*}{$\begin{array}{l}\text { Injury setbacks and } \\
\text { fitness issues (14) }\end{array}$} & $\begin{array}{l}\text { Internal } \\
\text { Iniurv-awareness (3) }\end{array}$ & & Being proactive and planning \\
\hline & $\begin{array}{l}\text { Injury-awareness (3) } \\
\text { Opportunistic, optimistic, and }\end{array}$ & & $\begin{array}{l}\text { ahead (3) } \\
\text { Changing personal priorities (1) }\end{array}$ \\
\hline & positive personality (4) & & Communicating with staff (1) \\
\hline & Patience (1) & & Quitting (2) \\
\hline & Resilience (3) & & Seeking social support (2) \\
\hline & External & & \\
\hline & Coach support (2) & & \\
\hline & National Lottery funding and & & \\
\hline & professional academies (1) & & \\
\hline & $\begin{array}{l}\text { Nurturing environment and access to } \\
\text { facilities (1) }\end{array}$ & & \\
\hline & Parental and partner support (1) & & \\
\hline & Scholarship (1) & & \\
\hline
\end{tabular}




\begin{tabular}{|c|c|}
\hline Transitional demand & Resources utilized \\
\hline $\begin{array}{l}\text { Performance setbacks } \\
\text { (9) }\end{array}$ & $\begin{array}{l}\text { Support staff (4) } \\
\text { Internal } \\
\text { Career-awareness (1) } \\
\text { Dedication and strong work ethic (2) } \\
\text { Desire for and openness to learning } \\
\text { and challenge (2) } \\
\text { Resilience (8) } \\
\text { Self-awareness (1) } \\
\text { External } \\
\text { Coach support (2) } \\
\text { High quality academic course (1) } \\
\text { Non-sport housemates (2) } \\
\text { Nurturing environment and access to } \\
\text { facilities (1) }\end{array}$ \\
\hline $\begin{array}{l}\text { Training and lifestyle } \\
\text { expectations (11) }\end{array}$ & $\begin{array}{l}\text { Internal } \\
\text { Appreciation of others (2) } \\
\text { Dedication and strong work ethic (3) } \\
\text { Desire for and openness to learning } \\
\text { and challenge (1) } \\
\text { Honesty, humility, and integrity (1) } \\
\text { Interpersonal skills (1) } \\
\text { Opportunistic, optimistic, and } \\
\text { positive personality (1) } \\
\text { Organization and time-management } \\
\text { (3) } \\
\text { Patience (1) } \\
\text { Personal decision making ability (1) }\end{array}$ \\
\hline
\end{tabular}

\section{External}

Breakdown in coach-athlete

relationship (1)

National Lottery funding, academies,

and talent identification programs

fostering misperceptions of status (3)

Parental overprotection (1)

Society and celebrity culture (1)
Coping strategies implemented

Being proactive and planning ahead (2)

Communicating with staff (1)

Displaying openness to learning and challenge (2)

Goal setting (1)

Quitting (1)

Seeking social support (2)
Being proactive and planning ahead (4)

Changing personal priorities (2)

Communicating with staff (3)

Displaying openness to learning and challenge (3)

Observational learning and social

comparison (8)

Overcommitting (1)

Quitting (1)

Seeking social support (4) 


\begin{tabular}{|c|c|c|c|}
\hline Transitional demand & Resources utilized & Barriers encountered & Coping strategies implemented \\
\hline \multirow{28}{*}{$\begin{array}{l}\text { Continued increase of } \\
\text { performance level (3) }\end{array}$} & Self-awareness (2) & & \\
\hline & Self-discipline (5) & & \\
\hline & & External & \\
\hline & External & Lack of understanding from non-sport & \\
\hline & Coach support (8) & housemates (5) & \\
\hline & Elite role model peers (8) & Non-student performance squads’ & \\
\hline & National Lottery funding and & facility access (1) & \\
\hline & professional academies (2) & Overly competitive and intimidating & \\
\hline & Nurturing environment and access to & teammates (3) & \\
\hline & facilities(3) & Society and celebrity culture (1) & \\
\hline & $\begin{array}{l}\text { Presence of training group and } \\
\text { teammates ( } 7 \text { ) }\end{array}$ & & \\
\hline & Support staff (3) & & \\
\hline & Internal & & Being proactive and planning \\
\hline & Dedication and strong work ethic (7) & & ahead (8) \\
\hline & Desire for and openness to learning & & Changing personal priorities (4) \\
\hline & and challenge (2) & & Communicating with staff (2) \\
\hline & $\begin{array}{l}\text { Opportunistic, optimistic, and } \\
\text { positive personality ( } 2 \text { ) }\end{array}$ & & $\begin{array}{l}\text { Displaying openness to learning } \\
\text { and challenge (2) }\end{array}$ \\
\hline & Organization and time-management & & Observational learning and social \\
\hline & & & comparison (7) \\
\hline & Patience (1) & & Seeking social support (9) \\
\hline & Personal decision making ability (4) & & \\
\hline & Self-awareness (2) & & \\
\hline & & External & \\
\hline & External & Breakdown in coach-athlete & \\
\hline & Academic flexibility (3) & relationship (2) & \\
\hline & Academic staff (1) & Lack of understanding from non-sport & \\
\hline & Coach support (8) & housemates (1) & \\
\hline & Elite role model peers (6) & Overly competitive and intimidating & \\
\hline
\end{tabular}




\begin{tabular}{|c|c|c|c|}
\hline \multirow[t]{12}{*}{ Transitional demand } & Resources utilized & Barriers encountered & Coping strategies implemented \\
\hline & High quality academic course (5) & teammates (5) & \\
\hline & National Lottery funding and & Parental overprotection (2) & \\
\hline & professional academies (3) & Pressure from university reputation (1) & \\
\hline & Non-sport housemates (2) & Society and celebrity culture (1) & \\
\hline & $\begin{array}{l}\text { Nurturing environment and access to } \\
\text { facilities (13) }\end{array}$ & & \\
\hline & Parental and partner support (3) & & \\
\hline & Presence of training group and & & \\
\hline & teammates (8) & & \\
\hline & Scholarships (1) & & \\
\hline & Support programs (1) & & \\
\hline & Support staff (5) & & \\
\hline \multicolumn{4}{|c|}{ Academic/vocational level } \\
\hline \multirow{16}{*}{$\begin{array}{l}\text { Course requirements } \\
\text { (9) }\end{array}$} & Internal & & Being proactive and planning \\
\hline & Career-awareness (1) & & ahead (14) \\
\hline & Dedication and strong work ethic (3) & & Changing personal priorities (2) \\
\hline & Desire for and openness to learning & & Communicating with staff (8) \\
\hline & and challenge (2) & & Displaying openness to learning \\
\hline & Interpersonal skills (2) & & and challenge (5) \\
\hline & $\begin{array}{l}\text { Opportunistic, optimistic, and } \\
\text { positive personality ( } 4 \text { ) }\end{array}$ & & $\begin{array}{l}\text { Observational learning and social } \\
\text { comparison (2) }\end{array}$ \\
\hline & Organization and time-management & & Seeking social support (1) \\
\hline & (7) & & \\
\hline & Personal decision making ability (4) & & \\
\hline & Self-discipline (3) & & \\
\hline & & External & \\
\hline & External & Affiliation with local college creating & \\
\hline & Academic flexibility (8) & discontinuity in academic expectation & \\
\hline & Academic staff (1) & $(2)$ & \\
\hline & Coach support (15) & Societal emphasis on higher education & \\
\hline
\end{tabular}




\begin{tabular}{|c|c|c|c|}
\hline Transitional demand & Resources utilized & Barriers encountered & Coping strategies implemented \\
\hline \multirow{19}{*}{$\begin{array}{l}\text { Post-university career } \\
\text { (8) }\end{array}$} & Elite role model peers (1) & (1) & \multirow{19}{*}{$\begin{array}{l}\text { Being proactive and planning } \\
\text { ahead (5) } \\
\text { Changing personal priorities (3) } \\
\text { Communicating with staff (9) } \\
\text { Displaying openness to learning } \\
\text { and challenge (2) }\end{array}$} \\
\hline & High quality academic course (1) & & \\
\hline & Nurturing environment and access to & & \\
\hline & facilities (1) & & \\
\hline & Parental and partner support (1) & & \\
\hline & Support staff (8) & & \\
\hline & Internal & & \\
\hline & Appreciation of others (2) & & \\
\hline & Career-awareness (7) & & \\
\hline & Interpersonal skills (3) & & \\
\hline & Opportunistic, optimistic, and & & \\
\hline & positive personality (1) & & \\
\hline & Personal decision making ability (2) & & \\
\hline & External & & \\
\hline & Academic staff (2) & & \\
\hline & Coach support (6) & & \\
\hline & High quality academic course (1) & & \\
\hline & Support programs (2) & & \\
\hline & Support staff (1) & & \\
\hline \multirow{10}{*}{$\begin{array}{l}\text { Psychological level } \\
\text { Developing identity } \\
\text { (1) }\end{array}$} & & & \multirow{10}{*}{$\begin{array}{l}\text { Being proactive and planning } \\
\text { ahead (2) } \\
\text { Changing personal priorities (1) } \\
\text { Communicating with staff (1) } \\
\text { Observational learning and social } \\
\text { comparison (1) }\end{array}$} \\
\hline & Internal & \multirow{9}{*}{$\begin{array}{l}\text { External } \\
\text { National Lottery funding, academies, } \\
\text { and talent identification programs } \\
\text { fostering misperceptions of status (3) }\end{array}$} & \\
\hline & Self-awareness (2) & & \\
\hline & & & \\
\hline & External & & \\
\hline & Coach support (1) & & \\
\hline & Elite role model peers (1) & & \\
\hline & High quality academic course (1) & & \\
\hline & Non-sport housemates (1) & & \\
\hline & Support programs (1) & & \\
\hline
\end{tabular}




\begin{tabular}{|c|c|c|c|}
\hline Transitional demand & Resources utilized & Barriers encountered & Coping strategies implemented \\
\hline \multirow{16}{*}{$\begin{array}{l}\text { Establishing personal } \\
\text { motivation (4) }\end{array}$} & Support staff (2) & \multirow{16}{*}{$\begin{array}{l}\text { External } \\
\text { National Lottery funding, academies, } \\
\text { and talent identification programs } \\
\text { fostering misperceptions of status (2) } \\
\text { Overly competitive and intimidating } \\
\text { teammates (1) } \\
\text { Society and celebrity culture (1) }\end{array}$} & \multirow{16}{*}{$\begin{array}{l}\text { Being proactive and planning } \\
\text { ahead (5) } \\
\text { Changing personal priorities (5) } \\
\text { Communicating with staff (1) } \\
\text { Displaying openness to learning } \\
\text { and challenge (2) } \\
\text { Goal setting (1) } \\
\text { Observational learning and socia } \\
\text { comparison (1) } \\
\text { Seeking social support (3) }\end{array}$} \\
\hline & Internal & & \\
\hline & Career-awareness (4) & & \\
\hline & Dedication and strong work ethic (2) & & \\
\hline & Honesty, humility, and integrity (1) & & \\
\hline & $\begin{array}{l}\text { Opportunistic, optimistic, and } \\
\text { positive personality (1) }\end{array}$ & & \\
\hline & Personal decision making ability (1) & & \\
\hline & Self-awareness (4) & & \\
\hline & External & & \\
\hline & Coach support (3) & & \\
\hline & Elite role model peers (4) & & \\
\hline & High quality academic course (2) & & \\
\hline & Parental and partner support (2) & & \\
\hline & Presence of training group and & & \\
\hline & teammates (3) & & \\
\hline & Support staff (1) & & \\
\hline \multirow{12}{*}{$\begin{array}{l}\text { Looking after oneself } \\
\text { (2) }\end{array}$} & Internal & \multirow{12}{*}{$\begin{array}{l}\text { External } \\
\text { Breakdown in coach-athlete } \\
\text { relationship (1) } \\
\text { National Lottery funding, academies, } \\
\text { and talent identification programs } \\
\text { fostering misperceptions of status (1) } \\
\text { Parental overprotection (3) }\end{array}$} & Being proactive and planning \\
\hline & Organization and time-management & & ahead (2) \\
\hline & & & Changing personal priorities (1) \\
\hline & Self-discipline (1) & & Communicating with staff (3) \\
\hline & & & Displaying openness to learning \\
\hline & External & & and challenge (1) \\
\hline & Coach support (6) & & Observational learning and socia \\
\hline & Elite role model peers (1) & & comparison (2) \\
\hline & High quality academic course (3) & & Seeking social support (2) \\
\hline & Presence of training group and & & \\
\hline & teammates (1) & & \\
\hline & Support staff (1) & & \\
\hline
\end{tabular}




\begin{tabular}{|c|c|c|c|}
\hline Transitional demand & Resources utilized & Barriers encountered & Coping strategies implemented \\
\hline $\begin{array}{l}\text { Taking personal } \\
\text { responsibility (13) }\end{array}$ & $\begin{array}{l}\text { Internal } \\
\text { Career-awareness (6) } \\
\text { Dedication and strong work ethic (5) } \\
\text { Desire for and openness to learning } \\
\text { and challenge (2) } \\
\text { Honesty, humility, and integrity (1) } \\
\text { Interpersonal skills (3) } \\
\text { Organization and time-management } \\
\text { (2) } \\
\text { Personal decision making ability (10) } \\
\text { Self-awareness (4) } \\
\text { Self-discipline (1) } \\
\text { External } \\
\text { Coach support (12) } \\
\text { Elite role model peers (4) } \\
\text { High quality academic course (1) } \\
\text { Nurturing environment and access to } \\
\text { facilities (1) } \\
\text { Presence of training group and } \\
\text { teammates (4) } \\
\text { Support programs (1) } \\
\text { Support staff (2) }\end{array}$ & $\begin{array}{l}\text { External } \\
\text { Breakdown in coach-athlete } \\
\text { relationship (1) } \\
\text { National Lottery funding, academies, } \\
\text { and talent identification programs } \\
\text { fostering misperceptions of status (3) } \\
\text { Overly competitive and intimidating } \\
\text { teammates (3) } \\
\text { Parental overprotection (3) } \\
\text { Society and celebrity culture (1) }\end{array}$ & $\begin{array}{l}\text { Being proactive and planning } \\
\text { ahead (14) } \\
\text { Changing personal priorities (4) } \\
\text { Communicating with staff (9) } \\
\text { Displaying openness to learning } \\
\text { and challenge (6) } \\
\text { Goal setting (1) } \\
\text { Observational learning and socia } \\
\text { comparison (4) } \\
\text { Seeking social support (4) }\end{array}$ \\
\hline
\end{tabular}

Psychosocial level Change in coach and maintaining coachathlete relationship (5)

\section{Internal}

Appreciation of others (1)

Desire for and openness to learning and challenge (1)

Honesty, humility, and integrity (2)

Interpersonal skills (3)
Being proactive and planning ahead (2)

Communicating with staff (4) 


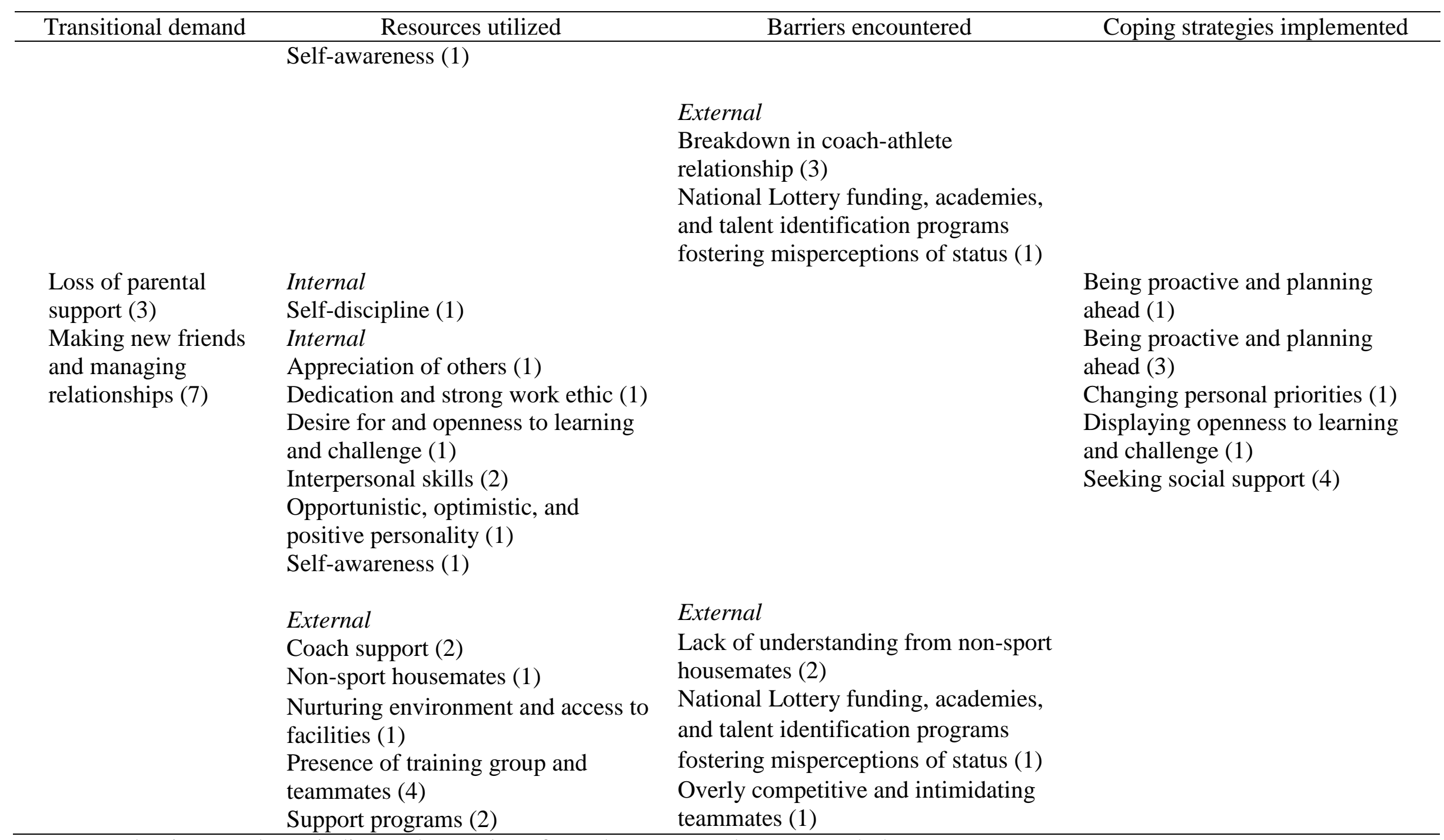

1 Note. Number in parentheses indicates the number of raw data quotes relevant to each theme. 